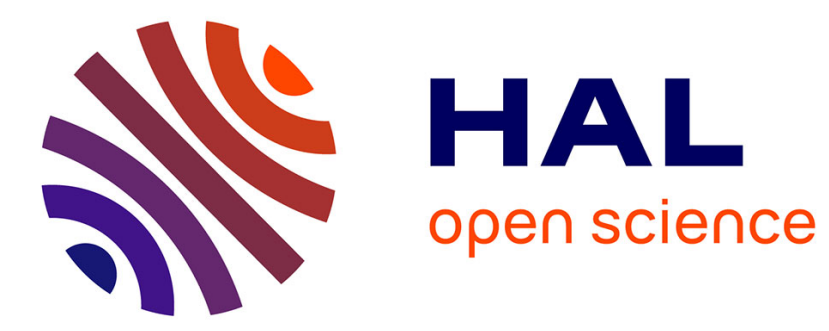

\title{
Intermittent signature of ENSO in west-Antarctic precipitation
}

Christophe Genthon, Emmanuel Cosme

\section{To cite this version:}

Christophe Genthon, Emmanuel Cosme. Intermittent signature of ENSO in west-Antarctic precipitation. Geophysical Research Letters, 2003, 30, 10.1029/2003GL018280 . hal-00203642

\section{HAL Id: hal-00203642 \\ https://hal.science/hal-00203642}

Submitted on 21 Aug 2020

HAL is a multi-disciplinary open access archive for the deposit and dissemination of scientific research documents, whether they are published or not. The documents may come from teaching and research institutions in France or abroad, or from public or private research centers.
L'archive ouverte pluridisciplinaire HAL, est destinée au dépôt et à la diffusion de documents scientifiques de niveau recherche, publiés ou non, émanant des établissements d'enseignement et de recherche français ou étrangers, des laboratoires publics ou privés. 


\title{
Intermittent signature of ENSO in west-Antarctic precipitation
}

\author{
Christophe Genthon and Emmanuel Cosme \\ Laboratoire de Glaciologie et Géophysique de l'Environnement, CNRS/OSUG, Saint Martin d'Hères, France
}

[1] Precipitation data from the new ERA40 reanalyses and from a 200-year simulation confirm a robust main mode of precipitation variability in west Antarctica. An intermittently strong ENSO signature is found in this mode. However, high correlation with ENSO indices appears infrequent. Thus, the high correlation found in ERA40, and previously in other chronologically realistic data, in the late 1980s and the 1990s may not be expected to last. Unlike previously suggested by others, the sign of the correlation between ENSO indices and west Antarctic precipitation, when significant, does not appear to change in time: Precipitation variability at the ENSO pace in the Bellingshausen-Weddell (Ross-Amunsden) region is consistently in phase (phase opposition, respectively) with the Southern Oscillation Index. This is consistent with a tropospheric wave train connecting the tropical Pacific and west Antarctic regions, which modulates in phase opposition the advection of air and moisture in the 2 regions. INDEX TERMS: 3349 Meteorology and Atmospheric Dynamics: Polar meteorology; 3354 Meteorology and Atmospheric Dynamics: Precipitation (1854); 1620 Global Change: Climate dynamics (3309); 1655 Global Change: Water cycles (1836); 9310 Information Related to Geographic Region: Antarctica; KEYWORDS: Antarctic precipitation, interannual/ interdecadal variability, El Nino Southern Oscillation, ERA40 reanalysis, surface mass balance. Citation: Genthon, C., and E. Cosme, Intermittent signature of ENSO in west-Antarctic precipitation,

\section{Introduction}

[2] Hints of an ENSO signature in Antarctic precipitation have been reported in the past [e.g., Cullather et al., 1996; Bromwich et al., 2000] and challenged [e.g., Genthon and Krinner, 1998]. Largely facing the Pacific ocean, west Antarctica is likely the Antarctic region most directly exposed to ENSO. Tropospheric wave trains [Trenberth and Carron, 2000; Kidson and Renwick, 2002] have indeed been identified, which connect the tropical Pacific to the west Antarctic seas and coasts at the ENSO pace. From meteorological analyses and climate model results, Genthon et al. [2003] show that the Antarctic tropospheric circulation variability is dominated by two modes, a 1st one related to the Antarctic Oscillation (AAO), and a 2nd one to the ENSO. Both modes have a strong pole of variability in west Antarctica. Thus, through direct air advection considerations, west Antarctic precipitation may be expected to at least partially covariate with the AAO and ENSO. Indeed, by analyzing precipitation data from climate models and meteorological-analyses-based short-term forecasts, the authors confirm that both the AAO and ENSO sign in the variability of precipitation in Antarctica.

[3] However, the recent record indicates that the signature of ENSO in the Antarctic precipitation was very strong in the 1990s but insignificant in an earlier period. Intermittence in the signature of ENSO in Antarctic precipitation is thus a plausible hypothesis, which could contribute to explaining why direct evidences of such a signature have been elusive. It also raises questions on the processes that relate climate variability in the Antarctic region with the lower latitudes, and how such variability can be recorded in snow and ice pits and cores. The object of the present letter is to alert the reader to and provide convincing support for the intermittence hypothesis, so far clearly identified in a limited range of data and in the last $\sim 25$ years of the 20th century only.

[4] To do so, longer and alternative datasets are used, namely the new ERA40 meteorological reanalysis and forecasts database, and a 200-year coupled atmosphereocean general circulation model (AOGCM) simulation, both of which are presented in section 2 along with the analysis methods. Section 3 shows that the coupled AAO/ENSOrelated mode of variability of Antarctic precipitation, previously identified by Genthon et al. [2003] in other datasets, is further confirmed here. Section 4 demonstrates intermittence of an ENSO signature in west Antarctic precipitation in the 2 datasets. Section 5 provides a brief discussion and a conclusion. In the remaining of this letter, GO3 will be used as a short for Genthon et al. [2003].

\section{Data and Methods}

[5] The European Center for Medium-range Weather Forecasts (ECMWF, Reading, UK) has recently completed a new multi-year meteorological reanalysis database (http:// www.ecmwf.int/research/era/). Compared to ERA15, the first ECMWF reanalysis [Gibson et al., 1997], ERA40 covers a much longer time span (September 1957 to august 2002 presently), it uses more up-to-date analysis and forecasting numerical tools, and it uses more observations. A preliminary evaluation [Genthon, 2003] suggests that several aspects of the Antarctic climate have improved in ERA40, compared to ERA15. For a wider use of ERA40, a much more extensive evaluation and validation work is needed, the results of which are not yet available. However, because the results presented here are consistent and extend those previously obtained with ERA15, with other analyses, and with climate models, the ERA40 data are deemed appropriate at this time for our purpose.

[6] The ERA40 precipitation data used here are from the $12 \mathrm{~h}$ and $24 \mathrm{~h}$ forecasts initialized from the meteorological analyses. Genthon [2003] shows that through the first few 

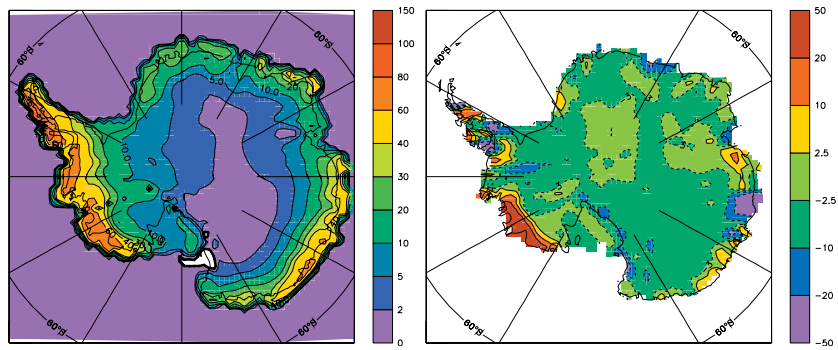

Figure 1. Left: ERA40 mean surface mass balance (precipitation minus evaporation). Right: Difference with the Vaughan et al. [1999] surface mass balance compilation/ interpolation. Unit: $\mathrm{cm}$ equivalent water per yr.

hours of forecast, the realism of precipitation is significantly affected by spin up from the initial conditions. As a trade-off between spin up and observational control in the early part of the forecasts, the $24 \mathrm{~h}$ minus $12 \mathrm{~h}$ forecasts are used here [e.g., see Genthon and Krinner, 1998]. Observations are too sparse and unreliable for a thorough analysis of precipitation in Antarctica, or even for an evaluation the quality of a product like ERA40. On the other hand, the net surface water balance can be evaluated from glaciological measurements. For this matter, the Antarctic surface mass balance of ERA40, calculated as precipitation minus evaporation, is in relative agreement with observations (Figure 1). In particular, it appears too dry in the remote interior, but the same typical differences with Vaughan et al. [1999]'s glaciological map as those found in other highresolution models [Genthon and Krinner, 2001] are also found here (Figure 1). The nominal spatial resolution of the ERA40 precipitation data is that of the Gaussian reduced T106 grid, here interpolated on a $1^{\circ} \times 1^{\circ}$ grid. The monthly record for the period 1958 to 2001 is used here.

[7] Data from a 240-year simulation of the HADCM3 AOGCM, produced by the Hadley Center for Climate Prediction (UK) and distributed by the IPCC Data Distribution Center (http://ipcc-ddc.cru.uea.ac.uk/) are also used here. The simulation is a reference current climate run with fixed $\mathrm{CO} 2$ and other atmospheric forcing. Evaporation is not available from this run, so that the surface mass balance on the Antarctic ice sheet cannot be fully evaluated. However, previous versions of the atmospheric component of the model have been favorably evaluated [Connolley and Cattle, 1994], and the precipitation map (not shown) is in good agreement with that of ERA40. The HADCM3 precipitation is on a $3.75^{\circ} \times 2.5^{\circ}$ grid on a monthly basis. The surface temperature, similarly sampled, is also used to calculate a model ENSO index (Section 3). Only the last 200 years of simulation, a sufficient sample for our purpose, are used here.

[8] To focus on interannual variability, data are timefiltered using a 25-month Hanning window that efficiently damps subannual variability at the cost of 12 months on each side of the series (GO3). Modes of variability are then extracted using empirical orthogonal function (EOF) analysis. Because precipitation is spatially sharply contrasted in the Antarctic region, the correlation matrix is used to calculate the EOFs. Thus, spatial modes and associated time series are all provided with arbitrary (but intercomparable) units. In addition, the datasets are area-weighted so

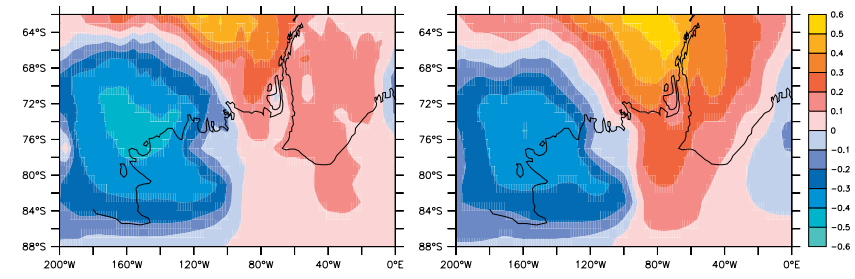

Figure 2. Main mode of west Antarctic precipitation variability from EOF analysis. Left: 2nd EOF from ERA40 (the 1st EOF is probably spurious, see text). Right: 1st EOF from HADCM3. Arbitrary units.

that their contribution in the correlation matrix is not biased due to the variable surface of the grid with latitude. To concentrate on the region where the strongest ENSO-related variability was previously identified by $\mathrm{GO} 3$, the study region for precipitation is limited to $0^{\circ}-200^{\circ} \mathrm{W}$ in longitude, $60^{\circ}-90^{\circ} \mathrm{S}$ in latitude.

\section{ENSO-Related Mode of Precipitation Variability}

[9] Figure 2 shows the 1st EOF of precipitation from HADCM3, and the 2nd EOF from ERA40. In the case of ERA40, the 1st EOF is affected by a sharp instationarity, whereby the associated time series is consistently positive (value near 1) before $\sim 1977$, then steps steeply down, and becomes consistently negative (value near -1 ) after $\sim 1981$. The source of this instationarity is not known. There is nothing similar in the NCEP (National Centers for Environmental Predictions) analyses (GO3), which at this time is the only other complete source of data over the same chronological period as ERA40. Although not demonstrated spurious here, the instationarity in the 1st ERA40 mode may be related to some change in the observations used in the analyses, e.g., satellite data that came in use at about the time of the sharp step. The 1st ERA40 EOF is thus ruled out here. Contamination of other EOFs cannot be excluded, however the 2nd EOF of ERA40 is quite consistent with the 1st HADCM3 EOF (Figure 2), as well as with the most robust precipitation EOF from other models and analysis

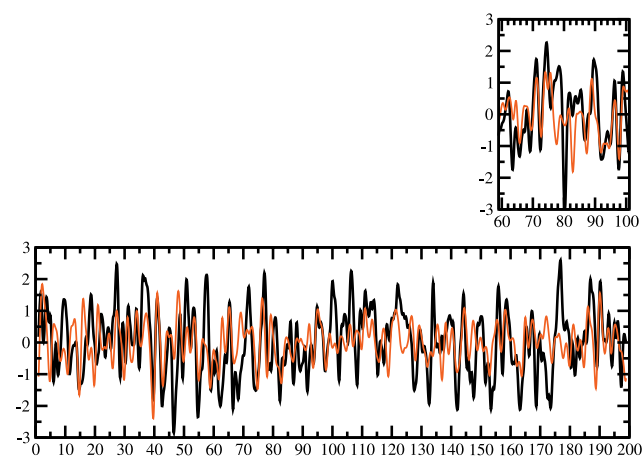

Figure 3. Time series (thick black lines) associated with the main modes of west Antarctic precipitation variability shown on Figure 2, for ERA40 (upper plot) and HADCM3 (lower plot). The real SOI (upper plot, divided by 10) and HADCM3 NINO34 index (lower plot, multiplied by -1) are also plotted (thin red lines). 
shown by GO3 (see their Figure 10). As previously mentioned, this mode shows an oscillating and alternating pattern between the Ross-Amundsen and the Bellingshausen-Weddell regions, although here (compared to GO3), the Weddell pole is slightly less marked as compared to the Bellingshausen area. This mode accounts for $23 \%$ (HADCM3) or $26 \%$ (ERA40, if the 1st EOF is excluded) of the variability of precipitation variability in the study domain, and is well separated from the following modes. From now on, this mode will be referred as the main mode of precipitation variability.

[10] Figure 3 shows the time series associated with the 2 EOFs shown in Figure 2. In the case of ERA40, the southern oscillation index (SOI, here the normalized pressure difference as observed at Tahiti and Darwin, available e.g., at http://www.dar.csiro,au.information/soi.html) is shown. In the case of HADCM3, the model NINO34 index is plotted. The NINO34 is the centered sea-surface temperature variation as averaged in the $170-120^{\circ} \mathrm{W}, 5^{\circ} \mathrm{N}-5^{\circ} \mathrm{S}$ region. The real NINO34 and SOI are very highly (anti)correlated and essentially interchangeable. For model results, the NINO34 is preferred because it is area-averaged and thus less sensitive to grid and resolution limitations. Examination of the characteristics of the HADCM3 NINO34 suggests that the model simulates a fairly realistic ENSO.

[11] The linear time correlation between the ERA40 EOF and the SOI is 0.49 . This is a highly significant correlation, even taking into account that the series are filtered as described in Section 2, thus reducing number of degrees of freedom of the series. However, this also indicate that the 2 series have only $\sim 25 \%$ of variability in common. The correlation between the HADCM3 NINO34 and EOF is also quite significant $(0.38)$ yet does not indicate a very strong contribution of ENSO to the variability of precipitation. There is thus much more than just ENSO in the main mode of variability, including some contribution of the AAO (GO3). However, visual examination of Figure 3 indicates that both for ERA40 and HADCM3, the signature of ENSO is intermittently high, and thus ENSO is a dominant contributor to variability, over periods of a decade or so, as further evidenced next.

\section{Intermittence of the Signature of ENSO in West Antarctic Precipitation}

[12] Figure 4 shows the 10 -year centered running correlations between the main precipitation EOFs as described in the previous section and ENSO indices. A t-test on autocorrelation-deflated series indicates that only time correlations above $\sim 0.7$ should be considered significant (above the 0.95 level) here, since they are calculated on 10-year filtered sampled (see e.g., GO3). The correlations between the main ERA40 mode and the SOI are always positive. They are quite high $(\sim 0.8)$ in the late 1980s and the 1990s, and insignificant from the mid-1970s through most of the 1980s. This is consistent with the results reported by GO3 from the NCEP reanalysis and from atmospheric model results. The results for ERA40 and NCEP do not agree well before the mid 1970s, but this is a period with less observational control in the analyses, and for which the reliability of the NCEP data is suggested unwarranted (GO3) while that of the ERA40 data has not been assessed.

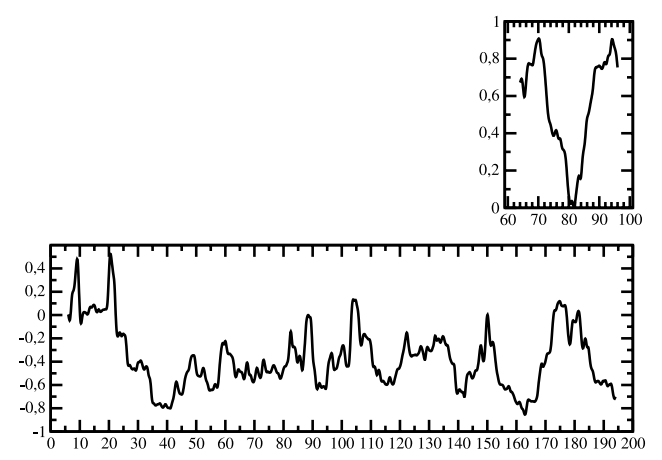

Figure 4. 10-year running correlations between the main mode of west Antarctic precipitation variability (Figure 3) and the SOI (upper plot, for ER40) and the HADCM3 NINO34 (lower plot). Only correlation above $\sim 0.7$ should be considered significant, see text.

[13] The time correlations between the HADCM3 main mode and NINO34 are almost consistently negative (when positive values occur, they are not significant). Because the NINO34 and SOI are anticorrelated, this is consistent with the positive sign of the correlations of ERA40, NCEP and other climate model results with the SOI. Thus, contrary to the suggestion by Bromwich et al. [2000], there is no evidence of changes in the sign of the correlations between west Antarctic precipitation and ENSO here. On the other hand, the HADCM3 data provide further evidence of intermittence in the (positive) correlations between a main precipitation variability mode and the SOI. Although not quite as high as for ERA40, 10-year correlations well above 0.7 occur in several instances in the record. However, according to the model, a strong signature of ENSO in west Antarctic precipitation is not a common feature: it may occur $10 \%$ of the time only. In such context, a high correlation in the 1990s, as revealed by ERA40 and other chronologically realistic data, may be somewhat exceptional, and it is unlikely to last through the XXIst century.

[14] Although the main mode of precipitation variability exhibited in Section 3 and Figure 2 is not a pure ENSO mode, correlations with ENSO indices indicate that no other mode obtained from EOF analysis carries a significant ENSO signature. It may be further demonstrated that the main mode on Figure 2 spatially describes how the ENSO signs in the precipitation variability of west Antarctica, by compositing those time samples of ERA40 or HADCM3 precipitation for which the 10-year centered correlation with NINO34 is above 0.7. The spatial structure of the main mode of variability calculated by EOF on such composite subsets is not shown here because it is very similar to the main mode displayed on Figure 2. More importantly, the fraction of variance accounted for is about twice during compositing periods than that when the full dataset is evaluated.

[15] A subset of ERA40 $500 \mathrm{hPa}$ geopotential height, obtained by compositing the same time samples as for the precipitation subset discussed above, is correlated with a corresponding composite of the SOI on Figure 5. The spatial distribution of the correlations is compared with the correlation map when the full dataset is used. Figure 5 shows that there is a much stronger dynamic link at the 

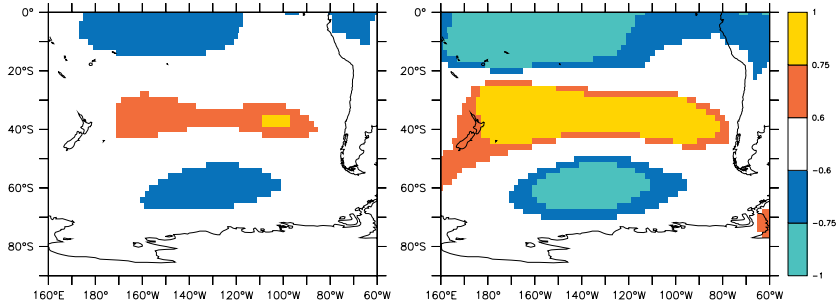

Figure 5. Spatial distribution of the correlations between ERA40 $500 \mathrm{hPa}$ geopotential height and the SOI, for the full 1958-2001 period (left), and for the periods of high correlation (above 0.7) with the main mode of west Antarctic precipitation variability (right).

ENSO pace between the tropics and west Antarctica, when the ENSO signs strongly in the west Antarctic precipitation. The link emerges as a wave train with 2 nodes, i.e. the sign of the ENSO-related geopotential anomaly off the west coast of Antarctica is the same as that over the tropical Pacific. Resulting air advection anomalies affect air moisture and thus precipitation in phase opposition in the RossAmundsen and the Bellingshausen-Weddell regions, with precipitation in the latter region fluctuating in phase with the SOI. This is all consistent with the precipitation analyses reported in section 3, and with the study by $\mathrm{GO} 3$ using other data. The $500 \mathrm{hPa}$ geopotential height data from the HADCM3 model are not available to us, but the mean sea-level pressure data agree with those from ERA40.

\section{Conclusion}

[16] Based on precipitation data from the new ERA40 reanalyses and from a 200-year simulation by the HADCM3 climate model, we confirm a robust main mode of precipitation variability in west Antarctica, which broadly opposes the Ross-Amundsen and the Bellingshausen-Weddell regions, as previously suggested by GO3 from other data. We also confirm that the ENSO signs significantly in this mode, and not significantly in other modes. However, both the ERA40 and HADCM3 data show that it does so intermittently along periods that span 10 to 15 years, and quite infrequently in the 200-year series from the climate model. Although the mechanism through which a link between the Pacific tropics and west Antarctica at the ENSO pace is intermittently established is not investigated here, it is clear that the atmospheric circulation is part of the game. A well-known west Antarctic low pressure, which is generally also largely related to the AAO, is modulated by the ENSO. This modulation appears to affect precipitation in the 2 regions of west Antarctica mentioned above, through air and moisture advection, thus a signature of ENSO in west Antarctic precipitation.

[17] It is found that, if intermittent, the ENSO signature in west Antarctic precipitation does not change sign. When significant, this signature is such that precipitation variability in the Bellingshausen-Weddell area is in (positive) phase with the SOI (and thus, the Ross-Amundsen area is in phase opposition). This is consistent with the fact that a 2-node mid-tropospheric (500 hPa geopotential height) wave train connects and imposes a same phase in the tropical Pacific and west Antarctic regions. From other data, Bromwich et al. [2000] have previously suggested that the correlation between precipitation in a sector of west Antarctica and the SOI has changed sign in time from the 1980s to the 1990s. We find here, rather, that the correlation is insignificant in the 1980s [in agreement with Genthon and Krinner, 1998] and large and positive in the 1990s. This is in agreement with a similar analysis of other data by GO3, and with the HADCM3 data over a much longer (200-year) series than is available from meteorological analyses.

[18] Intermittence in the ENSO signature in west Antarctic precipitation is probably one reason, along with convolution with other modes of precipitation variability (in particular, in relation with the AAO), why the signature of ENSO is hard to demonstrates from field data. In addition, direct precipitation and glaciological data are sparse and affected by various bias and noise problems, e.g., spurious deposition effects and large random variability at spatial scales which in practice cannot be sampled. Thus, climate model and meteorological analyses data remain a main source of information to evaluate Antarctic hydrology variability. Such data are not unquestionable though. It is thus important that data from various sources are used and to show that they confirm each other, which is the case for the results reported here.

[19] Acknowledgments. This work was made with support from the French Programme National d'Etudes de la Dynamique du Climat (PNEDC). Main data were obtained from the IPCC data distribution center (see section 2) and the European Center for Medium-range Weather Forecasts (ECMWF).

\section{References}

Bromwich, D. H., A. N. Rogers, P. Kallberg, R. L. Cullather, J. W. C. White, and K. J. Kreutz, ECMWF analyses and reanalyses of ENSO signal in Antarctic precipitation, J. Clim., 13, 2673-2690, 2000.

Connolley, W. M., and H. Cattle, The Antarctic climate of the UKMO unified model, Ant. Sci., 6, 115-122, 1994.

Cullather, R. I., D. H. Bromwich, and M. L. Van Woert, Interannual variations in Antarctic precipitation related to El Nino Southern Oscillation, J. Geophys. Res., 101, 19,109-19,118, 1996.

Genthon, C., Climate and surface mass balance of the polar ice sheets in ERA40/ERA15, ECMWF Re-analysis Project Report Series 3, ECMWF, Reading, UK, 299-316, 2003.

Genthon, C., and G. Krinner, Convergence and disposal of energy and moisture on the Antarctic polar cap from ECMWF reanalyses and forecasts, J. Clim., 11, 1703-1716, 1998.

Genthon, C., and G. Krinner, The Antarctic surface mass balance and systematic biases in GCMs, J. Geophys. Res., 106, 20,653-20,664, 2001.

Genthon, C., G. Krinner, and M. Sacchettini, Interannual Antarctic tropospheric circulation and precipitation variability, Clim. Dyn., doi: 10.1007/ s00382-003-0329-1, 2003

Gibson, J., P. Kallberg, S. Uppala, A. Noumura, A. Hernandez, and E. Serrano, ERA description, ECMWF Re-analysis Project Report Series, 3, ECMWF, Reading, UK, 77 pp., 1997.

Kidson, J. W., and J. A. Renwick, The Southern Hemisphere Evolution of ENSO during 1981-99, J. Clim., 15, 847-863, 2002.

Trenberth, K. E., and J. M. Carron, The southern oscillation revisited: Sealevel pressures, surface temperatures, and precipitation, J. Clim., 13, 4358-4365, 2000.

Vaughan, D. G., J. L. Bamber, M. Giovinetto, J. Russel, and P. R. Cooper, Reassessment of the net surface mass balance of Antarctica, J. Clim., 12, 933-946, 1999.

C. Genthon and E. Cosme, Laboratoire de Glaciologie et Géophysique de l'Environnement, BP 96, 38402 Saint Martin d'Hères Cedex, France. (genthon@lgge.obs.ujf-grenoble.fr) 